\title{
Positive surgical margins and local recurrence after simple enucleation and standard partial nephrectomy for malignant renal tumors: systematic review of the literature and meta-analysis of prevalence
}

\author{
Andrea MINERVINI ${ }^{1}$, Riccardo CAMPI ${ }^{1}{ }^{*}$, Francesco SESSA ${ }^{1}$, \\ Ithaar DERWEESH ${ }^{2}$, Jihad H. KAOUK ${ }^{3}$, Andrea MARI ${ }^{1}$, Koon H. RHA ${ }^{4}$, \\ Maurizio SESSA ${ }^{5}$, Alessandro VOLPE ${ }^{6}$, Marco CARINI ${ }^{1}$, Robert G. UZZO
}

${ }^{1}$ Department of Urology, Careggi Hospital, University of Florence, Florence, Italy; ${ }^{2}$ Department of Urology, UC San Diego Health System, La Jolla, CA, USA; ${ }^{2}$ Department of Urology, Glickman Urological and Kidney Institute, Cleveland Clinic, Cleveland, OH, USA; 4Department of Urology, Urological Science Institute, Yonsei University College of Medicine, Seoul, Republic of Korea; ${ }^{5}$ Department of Experimental Medicine, Section of Pharmacology "L. Donatelli", II University of Naples, Naples, Italy; 'Department of Urology, University of Eastern Piedmont, Novara, Italy; ${ }^{7}$ Division of Urologic Oncology, Fox Chase Cancer Center, Philadelphia, PA, USA

*Corresponding author: Riccardo Campi, Clinica Urologica I, Azienda Ospedaliera Careggi, Università di Firenze, Viale San Luca, 50134, Firenze, Italy. E-mail: riccardo.campi@gmail.com

\section{A B S T R A C T}

INTRODUCTION: The definition of the safest width of healthy renal margin to achieve oncological efficacy and therefore of the safest resection technique (RT) during partial nephrectomy (PN) continues to be widely debated. The aim of this study is to evaluate the prevalence of positive surgical margins (PSM), loco-regional recurrence (LRR) and renal recurrence (RER) rates after simple enucleation (SE) and standard partial nephrectomy (SPN) for malignant renal tumors. EVIDENCE ACQUISITION: A systematic review of the English-language literature was performed through August 2016 using the Medline, Web of Science and Embase databases according to the PRISMA criteria. A systematic review and meta-analysis was performed in those studies that defined the exact anatomical location of recurrence after PN. EVIDENCE SYNTHESIS: Overall, 33 studies involving 11282 patients were selected for quantitative analysis. At a median follow-up of 43 (SE) and 52 (SPN) months, the pooled estimates of the prevalence of PSMs, LRR and RER were $2.7 \%$ (95\% CI: $1.5-4.6 \%, \mathrm{P}<0.001)$ and0.4\% (95\% CI: $0.1-2.2 \%, \mathrm{P}=0.018), 2.0 \%(95 \% \mathrm{CI}: 1.4-2.8 \%, \mathrm{P}<0.001)$ and $0.9 \%$ (95\% CI: $0.5-1,7 \%, \mathrm{P}=0.04), 1.5 \%(95 \% \mathrm{CI}: 0.9-2.3 \%, \mathrm{P}=0.001)$ and $0.9 \%(95 \% \mathrm{CI}: 0.5-1,7 \%, \mathrm{P}=0.40)$ in patients undergoing SPN and SE, respectively.

CONCLUSIONS: Our systematic analysis and meta-analysis demonstrates that SE is noninferior to SPN regarding PSM, LRR and RER rates in patients undergoing PN for malignant renal tumors. Further studies using standardized reporting tools are needed to evaluate the role of resection techniques for oncologic outcomes after PN.

(Cite this article as: Minervini A, Campi R, Sessa F, Derweesh I, Kaouk JH, Mari A, et al. Positive surgical margins and local recurrence after simple enucleation and standard partial nephrectomy for malignant renal tumors: systematic review of the literature and meta-analysis of prevalence. Minerva Urol Nefrol 2017;69:

Key words: Recurrence - Margins of excision - Review - Enucleation - Nephrectomy.

\section{Introduction}

$\mathrm{P}$ artial nephrectomy (PN) is a recommended as a reference standard for the treatment of clinical T1 renal masses, mostly due to the potential benefit of renal function preservation. ${ }^{1,2}$ Indeed, the volume of preserved vascularized parenchyma represents a key deter- 
minant of functional recovery after surgery and it is strongly linked to both the tumor's anatomical complexity and the PN technique performed..$^{3-7}$

Nonetheless, the definition of the safest margin of healthy renal tissue that should be excised with the tumor and therefore of the oncologically safest resection technique (RT) during PN, has been the object of great debate within the urological community in the recent years. ${ }^{8}$ As such, the European Association of Urology (EAU) Guidelines recommendations changed dramatically during the last years. In 2010, they recommended the removal of a minimal tumor-free surgical margin to avoid local recurrence (yet without any reference to the specific RT), while the subsequent modification in 2013 outlined that if the tumor was completely resected, the thickness of surgical margin $(>1 \mathrm{~mm})$ did not correlate with the likelihood of local recurrence. Of note, from 2014 they do not provide any kind of recommendation regarding the optimal margin width and/ or the most appropriate RT during PN. Moreover, the lack of a standardized nomenclature of different RTs undermines the interpretation of such recommendations. ${ }^{9}$

In this scenario, the debate about the oncologic safety of enucleative PN (simple enucleation, SE) and the so-called standard PN (SPN) with a substantive parenchymal margin is still ongoing. $.8,10$

The aim of this systematic review and metaanalysis was to evaluate the prevalence of positive surgical margins (PSM), loco-regional recurrence (LRR) and renal recurrence (RER) rates after SE and SPN in studies with a minimum follow-up of 24 months.

\section{Evidence acquisition}

\section{Search strategy}

A systematic review of the literature was performed according to the Preferred Reporting Items for Systematic Reviews and MetaAnalyses (PRISMA) criteria. ${ }^{11}$ The research was restricted to articles published in the English language. The Medline, Web of Sci- ence and Embase databases were screened separately by two different authors (F.S. and R.C.) using two different queries in order to identify the articles which described the use of SE and SPN for the treatment of localized renal masses.

The first author screened all the articles indexed in the aforementioned databases from 01/01/2010 up to $18 / 08 / 2016$ using the following keywords or mesh terms: "nephron-sparing surgery" OR "conservative nephron surgery" OR "partial nephrectomy" OR "enucleation" OR "kidney sparing surgery" OR "nephron sparing resection" OR "enucleoresection". Moreover, "nephron sparing technique" OR "minimally invasive renal surgery" OR "kidney neoplasm surgery" [MeSH Major Topic] OR "kidney diseases/surgery" [MeSH Major Topic] OR "nephrectomy methods" [MeSH Major Topic] OR "minimally invasive surgical procedures/utilization" [MeSH Major Topic]. The second author performed a complementary search using the same databases from $01 / 01 / 2010$ up to $18 / 08 / 2016$ with the following keywords: "partial" AND "nephrectomy" OR "nephron-sparing surgery enucleoresection" AND "surgical margin*OR recurrence OR death OR metastasis. Moreover, survival

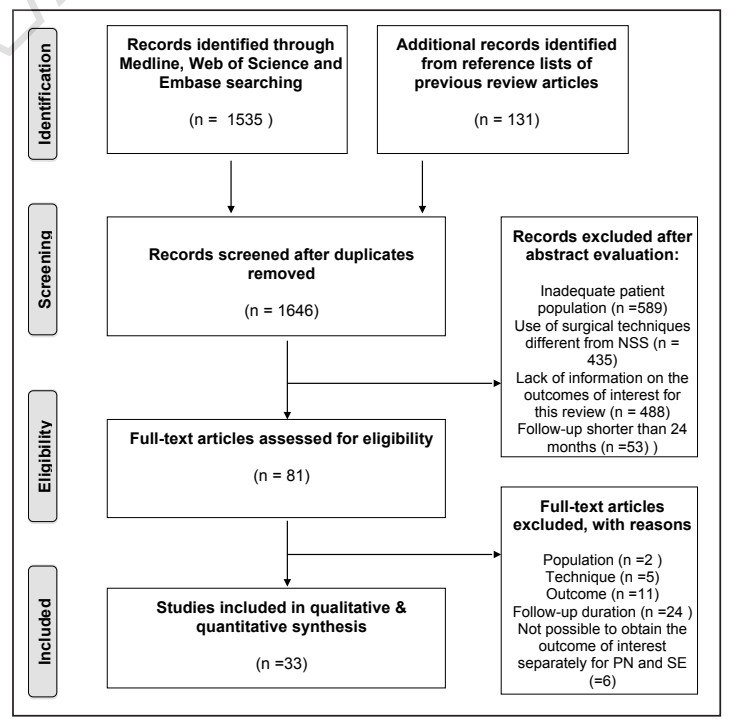

Figure 1.- Literature search and study selection process according to the Preferred Reporting Items for Systematic Reviews and Meta-Analyses (PRISMA) statement criteria. 
OR oncologic outcome* Enucleation" OR "enucleative" OR "enucleative" AND "partial nephrectomy" AND "surgical margin*" OR "recurrence" OR "death" OR "metastasis" OR "survival" OR "oncologic outcome*". In addition, both authors used the reference list of selected original articles and previous review articles on this topic for further eligible articles (Figure 1).

The list of articles judged highly relevant was reviewed by all co-authors and a final majority consensus was reached on the articles included.

\section{Definition of SE and SPN study groups}

Studies defining the RT as the excision of the tumor by blunt dissection following the natural cleavage plane between the peritumoral pseudocapsule and the renal parenchyma without removing a visible rim of healthy renal tissue 9, 12 were gathered in the SE group.

Conversely, the SPN group included all studies defining the RT as minimal margin PN, standard PN, enucleoresection or not specifying the amount of healthy renal tissue resected, as no validated definition of SPN was available in literature. ${ }^{9}$

Finally, in studies including both the SE and SPN techniques (i.e. comparative studies), patients were grouped separately within the two study groups for data analysis.

\section{Outcomes of interest}

The main outcomes of interest for this review were: 1) prevalence of PSM; 2) LRR rate and 3) renal recurrence rate (RER) after SE and SPN for malignant renal tumors.

Loco-regional recurrence was defined according to the EAU Guidelines as recurrence in the ipsilateral retroperitoneum, including renal parenchyma, lymph nodes or soft tissue, in the absence of distant metastasis. ${ }^{1}$ Renal recurrence was defined as the presence of local recurrence in the ipsilateral kidney, including the resection bed, the renal scar and the remaining kidney parenchyma in areas distant from the resection bed.

\section{Exclusion criteria}

The current review excluded studies including patients with solitary kidneys, genetic syndromes (i.e. Von-Hippel Lindau S., Birt-HoggDubè Syndrome etc.) and those articles that did not provide sufficient information to establish the outcome of interest for the surgical procedures included in this review. Moreover, in those studies providing accurate histological classification of renal tumors after NSS, we excluded patients with benign lesions from the quantitative analysis. Finally, whereas most relapses after NSS occur within a 2-year period, ${ }^{2}$ studies with a follow-period shorter than 24 months were excluded from our analysis.

\section{Data extraction}

Data were extracted independently by two authors (F.S. and R.C.) and were subsequently crosschecked. A data extraction form was developed a priori in order to collect, for each study, relevant information on study design, sample size, surgical technique, pathological Tumor Nodes and Metastasis (TNM) stage distribution, histological type, follow-up duration and recurrence data within 24 months. Moreover, PSM rate and the prevalence of LRR or RER in patients with PSM were recorded.

\section{Statistical analysis}

For descriptive purposes, boxplots were generated to provide summary measures of the median follow-up period, pTNM stage (if described), histologic type (clear cell renal cell carcinoma (RCC), papillary RCC, chromophobe RCC and other subtypes) separately for the SE and SPN groups.

Pooled estimates were calculated, as previously described in literature, ${ }^{13}$ for the prevalence of LRR, RER and PSM rates within 24 months after surgery. Fixed effect model and DerSimonian-Laird random-effects model were used separately for the two groups to provide a summary measure of the pooledeffect estimates and corresponding 95\% Confident Intervals (CI). The DerSimonian-Laird 
random-effects model was used to incorporate in the summary measures and the betweenstudy variability. Heterogeneity of the prevalence across studies was evaluated using the $\mathrm{Tau}^{2}{ }^{2}$ an estimate of the between-study variance in the random-effects meta-analysis and the $\mathrm{I}^{2}$ statistic. A sensitivity analysis for RER was performed separately for those studies that defined the exact anatomical location of recurrence (e.g. resection bed, ipsilateral kidney or retroperitoneal, etc.).

All analyses were performed using $\mathrm{R}$ (version 3.2.3, R Development Core Team, Vienna, Austria).

\section{Evidence synthesis}

Overall, 1666 potentially relevant articles were detected. After removal of 20 duplicates generated by the re-execution of the research query in multiple databases, 1646 articles were finally selected for abstract evaluation. Among these, 1565 papers were excluded due to inappropriate patient population $(\mathrm{N} .=589)$, use of surgical techniques different from NSS $(\mathrm{N} .=435)$, lack of information on the outcomes of interest for this review $(\mathrm{N} .=488)$ and followup shorter than 24 months $(\mathrm{N} .=53)$. As such, 81 papers were selected for full-text assessment of eligibility. Among these, 48 papers were excluded, including two for insufficient information regarding the study population, 5 for lack of detailed description of the surgical technique used to perform PN, 11 for lack of data on the outcome of interest and 24 studies due to the oncological follow-up period less than 24 months. Finally 6 studies were excluded as it was not possible to obtain the outcome

TABLE I.-Characteristics of the studies on standard partial nephrectomy (SPN) included in our review. Numbers and percentages are referred to the patient population with histologically confirmed malignant renal tumors.

\begin{tabular}{|c|c|c|c|}
\hline Study & 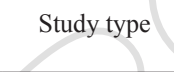 & N composilion (IV.) & Surgical technique \\
\hline Masson-Lecomte A & Prospective & 49-0 T1a, & Robotic \\
\hline Porpiglia F, 201215 & Prospective & & Laparoscopic \\
\hline Van Poppel H, 2010 & $\begin{array}{l}\text { Randomized } \\
\text { clinical trial }\end{array}$ & $268-105 \mathrm{~T} 1,110 \mathrm{~T} 2,12 \mathrm{~T} 3,0 \mathrm{~T} 4,41$ others & Open \\
\hline Becker F, 201118 & Retrospective & 66- $0 \mathrm{~T} 1 \mathrm{a}, 5 \mathrm{~T} 1 \mathrm{~b}, 45 \mathrm{~T} 2,16 \mathrm{~T} 3,0 \mathrm{~T} 4$ & Open; robotic \\
\hline Salami SS, 201429 & Retrospective & 1 & Laparoscopic \\
\hline Antic T, $2015^{30}$ & Retrospective & 406 - 299 T1a, 64 T1b, 14 T2, 29 T3, 0 T4 & Open; laparoscopic \\
\hline Saito H, $2012^{31}$ & Retrospective & / & Open; laparoscopic \\
\hline Minervini 201133 & Retrospective & 982- $727 \mathrm{~T} 1 \mathrm{a}, 176 \mathrm{~T} 1 \mathrm{~b}, 21 \mathrm{~T} 2,21 \mathrm{~T} 3,58$ others & Open \\
\hline Khalifeh A, 201339 & Retrospective & 500-296 T1a, 40 T1b, 4 T2,19 T3, 0 T4, 141 others & Robotic; laparoscopic \\
\hline Khalifeh A, 201340 & Retrospective & $943-763 \mathrm{~T} 1 \mathrm{a}, 107 \mathrm{~T} 1 \mathrm{~b}, 16 \mathrm{~T} 2,45 \mathrm{~T} 3,0 \mathrm{~T} 4,12$ others & Robotic \\
\hline Jeong SJ, $2010^{44}$ & Retrospective & $98-91 \mathrm{~T} 1 \mathrm{a}, 4 \mathrm{~T} 1 \mathrm{~b}, 0 \mathrm{~T} 2,2 \mathrm{~T} 3,0 \mathrm{~T} 4,1$ other & Open; laparoscopic \\
\hline Bigot P, 201445 & Retrospective & 126- 0 T1a, 0 T1b, 107 T2, 19 T3, 0 T4 & Open; robotic; laparoscopic \\
\hline Mullins JK, 201247 & Retrospective & 207- 168 T1a, 25 T1b,1 T2, 13 T3, 0 T4, & Robotic; laparoscopic \\
\hline Zargar K, $2015^{48}$ & Retrospective & 505- 393 T1a, 79 T1b, 16 T2, 17 T3, 0 T4, & Open; laparoscopic \\
\hline Ceccarelli G, 201351 & Retrospective & 28- 24 T1a, 3 T1b, 0 T2, 1 T3, 0 T4, & Robotic \\
\hline Komninos C, 201452 & Retrospective & 188- 128 T1a, 49 T1b,7 T2, 4 T3, 0 T4 & Robotic \\
\hline Koo Kc, 201453 & Retrospective & 82- $60 \mathrm{~T} 1,1 \mathrm{~T} 2,21 \mathrm{~T} 3,0 \mathrm{~T} 4$ & / \\
\hline Ha YS, 201354 & Retrospective & 423 -304 T1a, 119 T1b, 0 T2, 0 T3, 0 T4 & Open; robotic; laparoscopic \\
\hline Halachmi S, 201155 & Retrospective & / & Open \\
\hline Kreshover JE, 201356 & Retrospective & 360 -302 T1a, 58 T1b, 0 T2,0 T3, 0 T4, & Laparoscopic \\
\hline Liu Z,2012 57 & Retrospective & 168 -28 T1a, 140 T1b, 0 T2,0 T3, 0 T4, & Open; laparoscopic \\
\hline Di Pierro G, $2013{ }^{58}$ & Retrospective & 11- $11 \mathrm{~T} 1 \mathrm{a}, 0 \mathrm{~T} 1 \mathrm{~b}, 0 \mathrm{~T} 2,0 \mathrm{~T} 3,0 \mathrm{~T} 4$, & Laparoscopic \\
\hline Dulabon LM, 201059 & Retrospective & 333- $271 \mathrm{~T} 1 \mathrm{a}, 42 \mathrm{~T} 1 \mathrm{~b}, 4 \mathrm{~T} 2,16 \mathrm{~T} 3,0 \mathrm{~T} 4,4$ others & Robotic \\
\hline George AK, 201460 & Retrospective & / & Laparoscopic \\
\hline Breau RH, $2010^{61}$ & Retrospective & 69- 0 T1a, 0 T1b, 32 T2,37 T3, 0 T4, & Open \\
\hline Lane, BR 201362 & Retrospective & 1203-894 T1a, 227 T1b, 82 T2or higher & Open; laparoscopic \\
\hline Lane BR 201063 & Retrospective & 1260- 935 T1a, 235 T1b, 90 T2or higher & Open; laparoscopic \\
\hline Roos FC, 201164 & Retrospective & / & Open \\
\hline
\end{tabular}


of interest separately for the different surgical techniques performed.

In conclusion, 33 studies were selected for qualitative and quantitative analysis. Of note, only one study included both the SE and SPN techniques; in this case the patient cohorts were distributed in the two study groups for quantitative data analysis (Tables I, II). ${ }^{14-64}$

\section{Type of study and surgical technique}

Among the 33 studies selected for this review, $29(88 \%)$ were retrospective while $4(12 \%)$ were prospective, ${ }^{14-17}$ of which one was a randomized clinical trial. ${ }^{16}$ Thirty-two (97\%) studies provided specific information on the surgical approach performed during NSS. In most cases $(20 / 33,61 \%)$ an open surgical approach was used, either for the entire cohort
$(9 / 33,27 \%)$ or combined with laparoscopic or robotic techniques $(11 / 33,83 \%)$.

\section{Study population among the SE and SPN groups}

Overall, 11282 patients with histologically confirmed malignant renal tumors were included in the analysis, of which 9861 patients undergoing SPN and 1421 SE. The median follow-up period of the studies was 52 months for SPN (IQR 49-58 months, range 40-58) and 43 months for SE (interquartile range [IQR] 31-57, range 24-112) (Figure 2).

The distribution of pTNM stages was comparable between the SE and SPN groups (Figure 3). Specifically, among the studies that specifically defined the percentages of $\mathrm{pT}$ stage, the median rate of pT1a was 74\% (IRQ: $55-$

\begin{tabular}{|c|c|c|c|}
\hline $\begin{array}{c}\text { Follow-up } \\
\text { (median /mean) } \\
\text { (months) }\end{array}$ & & 4 rate $(\mathrm{N} ., \%)$ & $\begin{array}{c}\text { Recurrence rate } \\
\text { in patients with } \\
\text { PSM (N., \%) }\end{array}$ \\
\hline 26 & 33 clear cell, 13 papillary, 2 chromophobe, 6 other & $3 / 49(6)$ & $0 / 3(0)$ \\
\hline 48 & / & $0 / 41(0)$ & $0(0)$ \\
\hline 112 & 177 clear cell papillary and chromophobe not specif & $3 / 268(1)$ & / \\
\hline 28 & 51 clear cell, 9 papillary, 6 chromophobe, 25 others & / & / \\
\hline 43 & 7 clear cell, 1 papillary, 0 chromophobe, 1 other & $0 / 9(0)$ & $0(0)$ \\
\hline 33 & 243 clear cell, 77 papillary, 47 chromophobe, 39 others & $61 / 406(15)$ & $4 / 61$ \\
\hline 26 & 1049 clear cell,95 papillary, 36 chromophobe, 13 others & $26 / 1193(2)$ & $1 / 26(4)$ \\
\hline 52 & 755 clear cell, 151 papillary, 59 chromophobe, 17 others & $5 / 982(1)$ & / \\
\hline 24 & 236 clear cell, 86 papillary 21 chromophobe, 157 others & / & / \\
\hline 64 & 607 clear cell,223 papillary, 81 chromophobe, 32 others & $21 / 943(2)$ & $2 / 21(10)$ \\
\hline 71 & 86 clear cell, 9 papillary 3 chromophobe & $3 / 98(3)$ & $0 / 3(0)$ \\
\hline 30 & 74 clear cell, 34 papillary, 12 chromophobe, 6 others & $14 / 126(11)$ & / \\
\hline 28 & 143 clear cell,43 papillary, 21 chromophobe, & $5 / 207(2)$ & / \\
\hline 38 & 362 clear cell,98 papillary, 30 chromophobe, 15 others & $3 / 505(1)$ & / \\
\hline 28 & 19 clear cell, 0 papillary, 4 chromophobe, 5 others & $1 / 28(3)$ & / \\
\hline 43 & / & $10 / 188(5)$ & / \\
\hline 43 & 87 clear cell,5 papillary, 1 chromophobe, 11 others & $14 / 104(13)$ & $6 / 14(43)$ \\
\hline 84 & 423 clear cell, 0 papillary 0 chromophobe & / & / \\
\hline 55 & 201 clear cell, 28 papillary 0 chromophobe & / & / \\
\hline 66 & / & $13 / 360(4)$ & $1 / 13(8)$ \\
\hline 30 & 154 clear cell, 14 others & $1 / 168(1)$ & $0 / 1 / 0)$ \\
\hline 34 & 7 clear cell,3 papillary 0 chromophobe, 1 other & $1 / 11(9)$ & $0 / 1(0)$ \\
\hline 45 & 222 clear cell, 73 papillary 27 chromophobe, 1 other & $7 / 333(2)$ & $0 / 7(0)$ \\
\hline 42 & 245 clear cell, 87 papillary 26 chromophobe, 88 other & $6 / 355(2)$ & $0 / 6(0)$ \\
\hline 38 & 44 clear cell, 18 papillary 6 chromophobe, 1 other & / & / \\
\hline 84 & 835 clear cell, 368 other types & $7 / 1203(1)$ & $0 / 7(0)$ \\
\hline 54 & 878 clear cell, 383 other types & $7 / 1261(1)$ & $0 / 7(0)$ \\
\hline 55 & 39 clear cell, 19 papillary, 13 chromophobe, 2 others & / & / \\
\hline
\end{tabular}


TABLE II. - Characteristics of the studies on simple enucleation (SE) included in our review. Numbers and percentages are referred to the patient population with histologically confirmed malignant renal tumors.

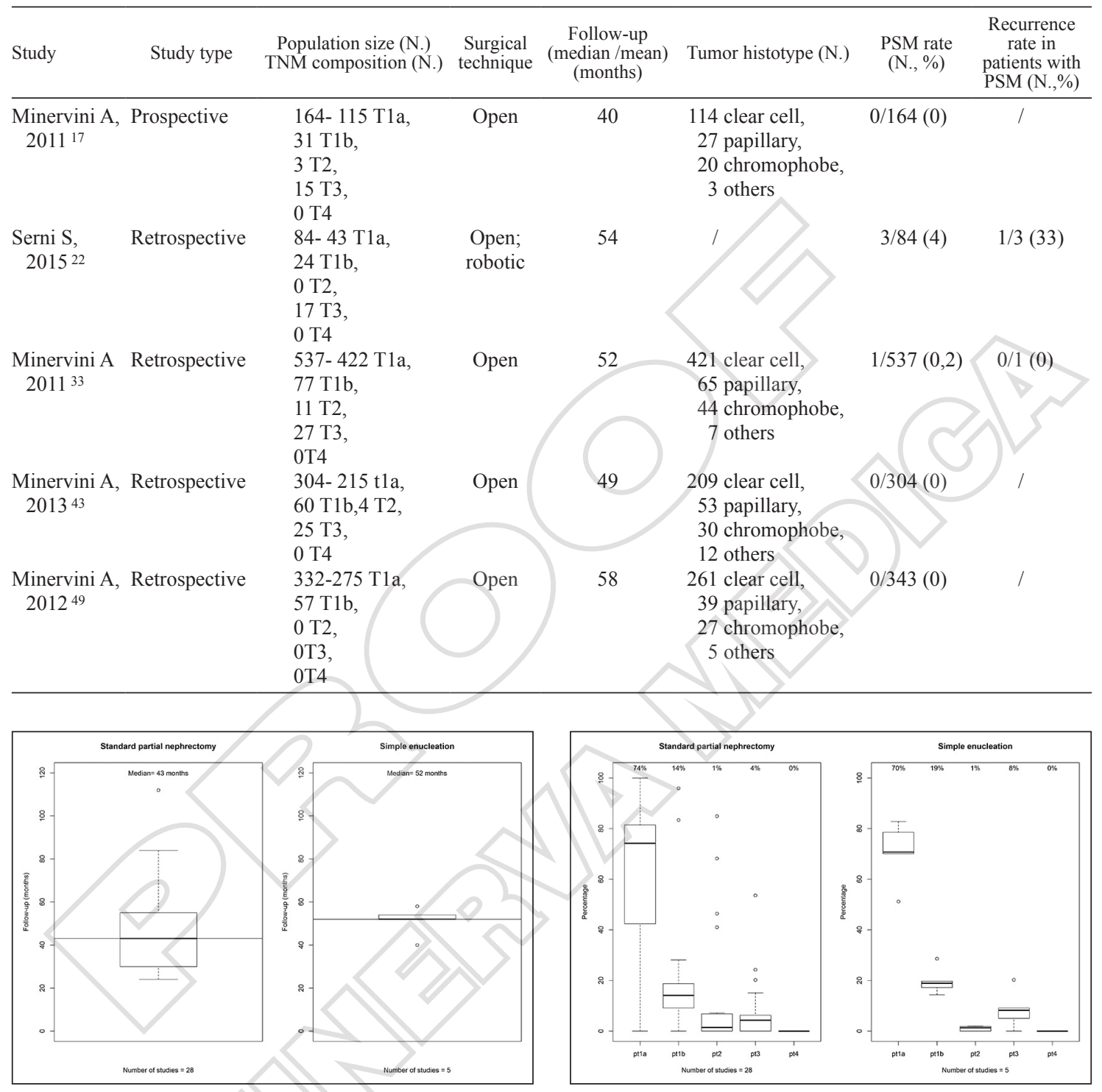

Figure 2.-Boxplots showing the median (IQR, range) duration of the follow-up period in the studies on standard partial nephrectomy and simple enucleation included in the review.

Figure 3.-Boxplots showing the median (IQR, range) percentage of the prevalence of tumor $\mathrm{pT}$ stages among the studies on standard partial nephrectomy and simple enucleation included in the review. Percentages are referred to the median value of each pT stage.

$81 \%$, range $0-100 \%$ ) for SPN and $70 \%$ (IRQ: range $0-54 \%)$. Of note, in two studies in the $70-79 \%$, range $51-83 \%$ ) for $\mathrm{SE}$, while the median rate of pT1b was 14\% (IRQ: $10-19 \%$, range $0-96 \%$ ) and 19\% (IRQ: $17-20 \%$, range $14-29 \%)$ for SPN and SE, respectively. The median rate of pT3 was $8 \%$ for SPN (IRQ: $5-9$ $\%$, range $0-20 \%$ ) and $4 \%$ for SE (IRQ: $1-6 \%$, SPN groups, the majority of patients included had pT2 malignant tumors. ${ }^{14,18}$

Similarly, the median rate of each histologic subtype at final histopathological analysis was comparable, with clear cell RCC (ccRCC) rates of $69 \%$ (IRQ: $65-78 \%$, range $53-100 \%$ ) 


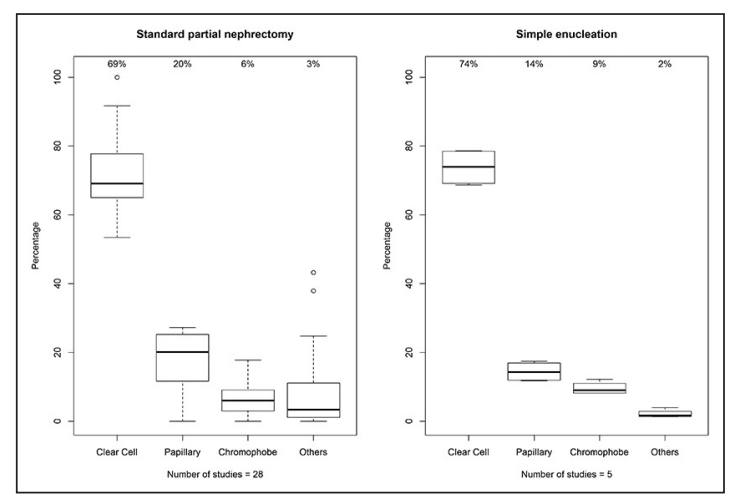

Figure 4.-Boxplots showing the median (IQR, range) percentage of prevalence of each tumor histotype among the studies on standard partial nephrectomy and simple enucleation included in the review. Percentages are referred to the median value of each histopathological subtype.

for SPN and 74\% (IRQ: 69-78\%, range 69$79 \%$ ) for SE and papillary RCC (pRCC) rates of $20 \%$ (IRQ: $12-25 \%$, range $0-27 \%$ ) for SPN and $14 \%$ (IRQ: $12-17 \%$, range $12-17 \%$ ) for SE. Chromophobe RCC (cRCC) was found in $6 \%$ (IRQ: $3-9 \%$, range $0-18 \%$ ) of cases in the SPN group and 9\% (IRQ: $8-10 \%$, range $8-12 \%$ ) in the SE group (Figure 4).

\section{Prevalence of PSMS}

The goal of PN is to obtain complete excision of the tumor with negative surgical margins while preserving as much healthy renal parenchyma as possible. In this context, the rate of PSMs has traditionally been associated with the amount of healthy renal tissue resected with the tumor and consequently with the different RT performed. ${ }^{19}$ Historically, the paradigm of SPN firstly introduced by Vermooten in 1950 involved the removal of a $1 \mathrm{~cm}$ margin of peritumor normal renal parenchyma to ensure a negative surgical margin. ${ }^{19}$ However, the current view favors a more conservative resection approach toward a minimal margin $\mathrm{SPN},{ }^{20}$ as the resection of $1 \mathrm{~cm}$ of healthy renal tissue might theoretically lead to an increased risk of intraoperative complications and may reduce the amount of preservable healthy parenchyma, which is key determinant of postoperative renal functional outcomes following NSS. ${ }^{21}$
At the same time, SE, initially proposed as an alternative RT for renal preservation in patients with renal insufficiency, solitary kidneys or hereditary cancer syndromes, has gained popularity in the last ten years due to the increasing evidence of its technical feasibility and long-term oncologic efficacy. ${ }^{10}$ Indeed, SE has been shown to be feasible and safe also for highly complex renal masses, such as completely endophytic or hilar tumors, where the excision of a large safety margin of normal parenchyma (advocated by the SPN technique) might increase the risk of intraoperative complications. ${ }^{19,} 22$ In addition, detailed histological reports on SE specimens demonstrated that even in cases of pseudocapsule infiltration, the constant presence of a thin microscopic layer of chronic inflammatory tissue prevented PSMs. ${ }^{23}$ These anatomo-pathological characteristics define a constant anatomic dissection plane (ADP) that represents a key landmark for surgeons during both blunt and sharp tumor excisions. In this scenario, both the SE and minimal margin SPN strategies are hinged into constant anatomical features of the tumorparenchymal interface ${ }^{8,24}$ and some authors have even considered SE the least minimalmargin SPN. ${ }^{8,} 25$

Overall, the question as to whether the type of RT performed during PN (SE vs. SPN) does affects the rate of PSMs is still matter of discussion. 10,26

Previous reviews on this topic have reported an overall incidence of PSM rates after NSS of $0-7 \% .{ }^{26,27}$ The incidence rate was comparable between open, laparoscopic and robotic approaches. ${ }^{27}$ Moreover, many histopathological reports highlighted the lack of association between the margin size of different RTs and recurrence of RCC and the long-term progression-free survival. 19,28

The prevalence of PSMs after SPN in our review ranged from $0 \%$ to $15 \%$ (Table I). Of note, in the retrospective study by Salami et $a l$. evaluating the results of laparoscopic offclamp SPN in a series of 9 hilar tumors, the prevalence of PSMs at a median follow-up of 43 months was $0 \%$ with no patient experiencing local recurrence. ${ }^{29}$ However, the authors 
stressed that a negative surgical margins did not necessarily translate into recurrence-free survival. ${ }^{29}$ On the contrary, in the retrospective cohort study by Antic et al., PSMs were recorded in 61/406 (15\%) patients with RCC after SPN, with 4/61 (7\%) patients with PSMs experiencing local recurrence (within the ipsilateral kidney) at a median follow-up of 33 months. The authors concluded that the type of RCC (tumor multifocality, grade and stage) might be more important than margin status on the development of local recurrence. ${ }^{30}$ The same conclusions were reached by Saito et al. in their large retrospective survey on 1193 patients with malignant RCC treated with SPN, where they showed a PSM rate of $2 \%$ and a local recurrence rate in patients with PSM of $4 \%$. As such, in their cohort the tumor recurrences occurred primarily as metastases (with or without local recurrence) and surgical margin status appeared to have little impact on oncological outcomes. ${ }^{31}$ Interestingly, even if not included in the quantitative analysis, in the study by Kopp et al. on the survival outcomes after SPN for clinical T2 renal tumors, there were only $2 / 89$ (2.2\%) PSMs. In this series, the 5-year progression-free survival (PFS), cancer-specific survival (CSS) and overall survival (OS) after SPN were 79.9\%, 86.7\% and $83.3 \%$, respectively. 32

PSM rate in the SE cohort according to our review ranged from $0 \%$ to $4 \%$ (Table II). In particular, in a large retrospective multicenter study by Minervini et al. comparing the oncologic outcomes of SE and SPN, PSM rate after SE was $1 / 537(0.2 \%)$ with 1 patient developing local recurrence at a median follow-up of 54 months. ${ }^{33}$ These findings have been distinctly confirmed by three high-quality, well-designed studies that are excluded from our meta-analysis due to a follow-up period shorter than 24 months 34,35 or lack of details on the anatomical sites of local recurrence. ${ }^{36}$

Indeed, Mukkamala et al. reported a PSM rate of $3 \%$ after SE - with $3(4 \%)$ cases developing local recurrence at a median followup of 36 months - compared to a PSM rate of $7 \%$ and a local recurrence rate of $4 \%$ in the cohort of patients undergoing SPN. ${ }^{36}$ In their matched-pair analysis aiming to compare the perioperative outcomes of SE versus SPN in clinical T1 renal tumors in a multicenter cohort of patients from high-volume centers, Longo et al. showed that the incidence of PSMs was significantly lower in patients treated with SE and 4.7 times higher in patients undergoing SPN. ${ }^{35}$ The same conclusions were reached by Schiavina et al. in a large multi-institutional prospective study evaluating the predictors of PSMs in patients undergoing PN at 19 Italian urological centres (RECORd Project). They found that PSMs rate was significantly lower in patients treated with SE compared to SPN (1.6\% vs. $7.4 \%$, respectively; $\mathrm{P}<0.0001)$ and that, on multivariable analysis, SPN, age, upper pole tumor location and Fuhrman 3-4 nuclear grade were independent predictors of PSMs. ${ }^{34}$ These findings suggest the close relationship between RT and PSMs rate after PN and the possible lower risks of well-performed SE for the achievement of negative margins.

Compared to the studies on SPN, the reports on SE showed a less variability in PSM rate (range $0-4 \%$ vs. $0-15 \%$ ), possibly due to both technical-related and methodological-related aspects. Indeed, most series on SE were performed in high-volume centers with extensive experience in the enucleative techniques (thus reducing the possibility of variable surgical outcomes across different surgeons and institutions), while the SPN group includes, by definition, different kinds of RTs and consequently possible variations in surgical margin width and status. Moreover, our review could not discriminate the various technical refinements of the SPN concept and grouped all the non enucleative RTs into the same study category. As such, this might have led to a selection bias when analyzing the rate of PSM after SPN.

Overall, our meta-analysis showed that, at a median follow-up of 43 and 52 months, the pooled estimations of the prevalence of PSMs in patients undergoing SPN and SE were $2.7 \%\left(95 \% \mathrm{CI}: 1.5-4.6 \%, \mathrm{tau}^{2}=1.435\right.$, $\left.\mathrm{I}^{2}=92.4 \%, \mathrm{P}<0.001\right)$ and $0.4 \%(95 \% \mathrm{CI}: 0.1-$ $\left.2.2 \%, \operatorname{tau}^{2}=2.246, \mathrm{I}^{2}=66.3 \%, \mathrm{P}=0.018\right)$. These results suggested strong evidence against the null hypothesis of differences in the pooled 


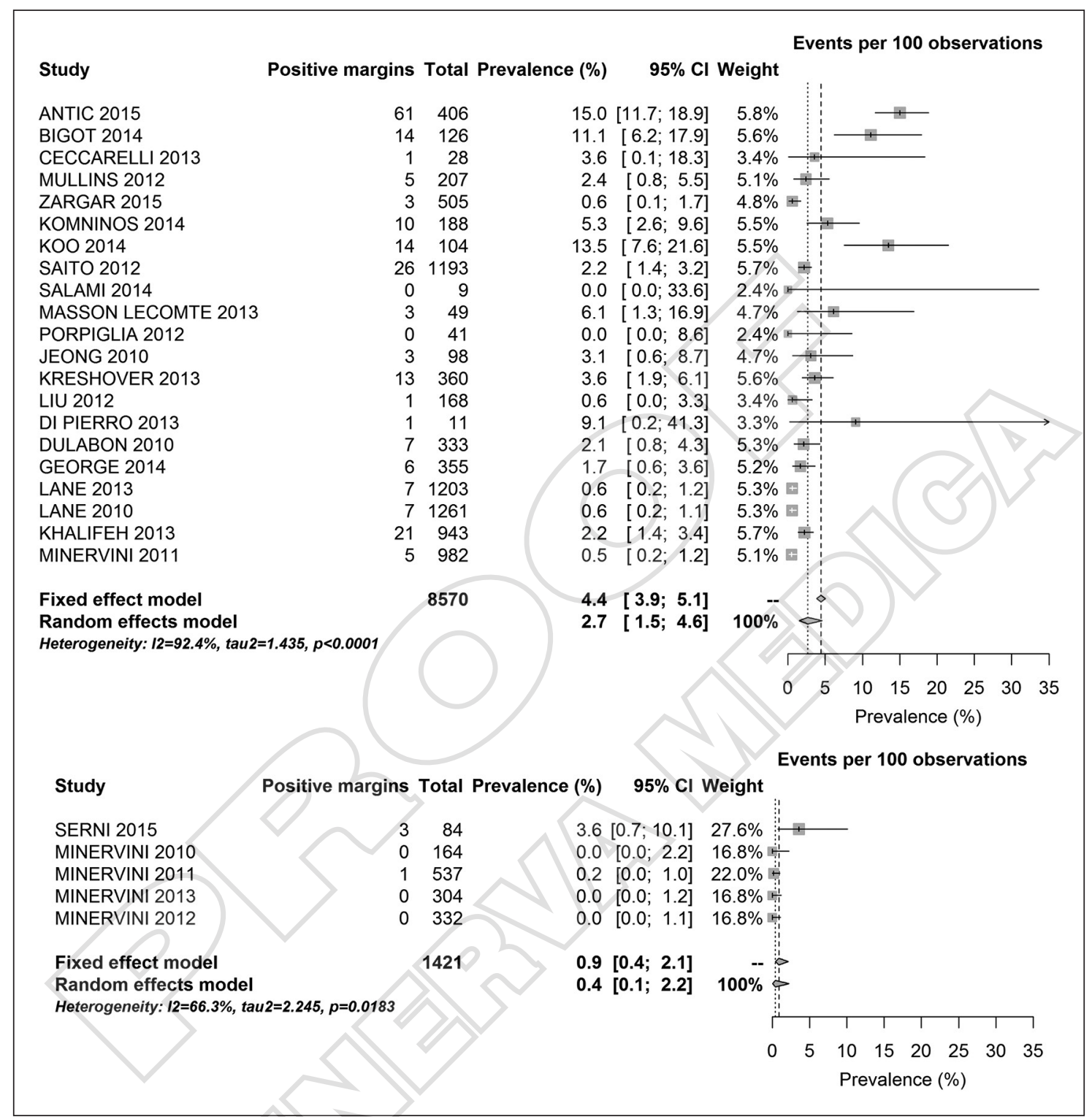

Figure 5.-Forest plot of the crude and pooled prevalences of positive surgical margin among the studies on standard partial nephrectomy and simple enucleation included in the review.

prevalence of PSMs among patients undergoing SPN compared to those undergoing SE, as clearly evidenced by the overlapping of the 95\% confident intervals (Figure 5). ${ }^{14-63}$

Although the ranges clearly differed between SE and SPN, the pooled estimated prevalence of PSM were comparable between the two groups in our meta-analysis, highlighting that SE is at least non inferior to traditional SPN in terms of margin status. In the study by
Minervini et al., included in our analysis, the PSM rate was $0.2 \%$ after SE and $0.5 \%$ after SPN. ${ }^{31}$ This findings are confirmed by the retrospective study conducted by Mukkamala et al. that, although not included in our review for quantitative analysis, reported a slightly lower rate of PSM after SE compared to SPN (3vs. 7\% ${ }^{32}$ ). In light of the peculiar anatomical characteristics of the kidney tumor-parenchymal interface ${ }^{23,24}$ and the constant presence of 
a microscopic layer of tissue after SE, 12 a possible technical explanation of the lower rate of PSM after SE in some recent series 33,36 might be that during SE the surgeon "keeps always an eye" on the tumor margin avoiding entry into the tumor. ${ }^{37}$ An alternative explanation includes that larger, more infiltrative tumors are less amenable to SE and therefore harder to achieve a NSM.

Overall, the available evidence supports the non-inferiority of SE compared to SPN with regards to PSMs rate after PN and the potential benefits of the enucleative technique in well-selected patients. However, due to the retrospective and hypothesis-forming nature of most series and the lack of standardized reporting of RTs in PN literature, no definitive conclusions can be drawn to date on the oncological advantage of a specific RT over the others. What is shown in our review and meta-analysis is that, in the absence of well-controlled randomized trials, SE does not compromise oncological outcomes after PN and may actually provide technical, functional and oncological benefits in selected patients.

\section{Prevalence of local recurrence after SPN and SE}

Local recurrence rates after $\mathrm{PN}$ have been shown to be less than $5 \%$ and equivalent to those of radical nephrectomy. 19,38 Traditionally, causes of local recurrence include incomplete removal of the tumor, multifocality or new tumor formation in areas different from the resection bed. Whether or not a PSM is a risk factor for disease recurrence after PN has been controversial;26, 27 however, the current view is that patients with PSMs harbor an increased risk of disease recurrence (especially in highly malignant tumors) but do not seem to influence overall survival and cancer-specific survival. ${ }^{39-41}$ To this regard, an accurate evaluation of the impact of PSMs on the development of local recurrence after PN requires a careful assessment of tumor features (including tumor histotype, stage and complexity), resection technique and quality of histopathological reporting (i.e. exclusion of false PSM) in order to obtain a balanced, evidence-based interpretation of the current studies.

The oncologic safety of SE has been demonstrated by multiple retrospective and prospective studies showing that the surgical margin width was not associated with the oncological prognosis. ${ }^{42-44}$ Moreover, several reports have confirmed acceptable oncologic results of SE and some have demonstrated similar local recurrence-free survival and cancer specific survival rates between SE and SPN. One study also confirmed similar cancer specific survival rates between SE and radical nephrectomy. ${ }^{19}$

In this context we performed a systematic analysis on the rate of local recurrence after SE and SPN with a special emphasis on the recurrence pattern and location. As previously explained, LRR has been defined as local recurrence in the ipsilateral retroperitoneum, while RER as recurrence in the ipsilateral kidney (with or without mention of the possible involvement of the resection bed). The need to perform a systematic analysis on the recurrence rate after SE and SPN separately for LRR and RER is based on the hypothesis that such entities include diseases with specific pathophysiologic risks (i.e. lymphovascular invasion for retroperitoneal lymph node involvement vs. residual tumor growth for recurrences at the surgical site of resection).

According to our analysis, among the studies grouped in the SPN group the prevalence of LRR varied from $0 \%$ to $9 \%$ (Table I). In series including patients with $\mathrm{pT} 1 \mathrm{a}$ or $\mathrm{pT} 1 \mathrm{~b}$ renal masses, the LRR was as low as $0-4 \% .30,31,47,48$

Of note, the study by Bigot et al. reporting a recurrence rate of $9 \%$ at a median follow-up of 30 months included only patients with pT2 or pT3 renal tumors. ${ }^{45}$ However, the study by Kopp et al. showed that the survival outcomes of SPN for cT2 renal masses were comparable to those of radical nephrectomy (RN) after controlling for R.E.N.A.L. nephrometry score (5-year PFS and CSS of $69.8 \%$ vs. $79.9 \%$ $(\mathrm{P}=0.115)$ and $82.5 \%$ vs. $86.7 \%$ for $\mathrm{PN}$ and $\mathrm{RN}$, respectively). ${ }^{32}$ Moreover, using a large national cancer database, Alanee et al. showed no difference in recurrence rate between PN and $\mathrm{RN}$ in patients with $\mathrm{cT} 2$ renal tumors con- 


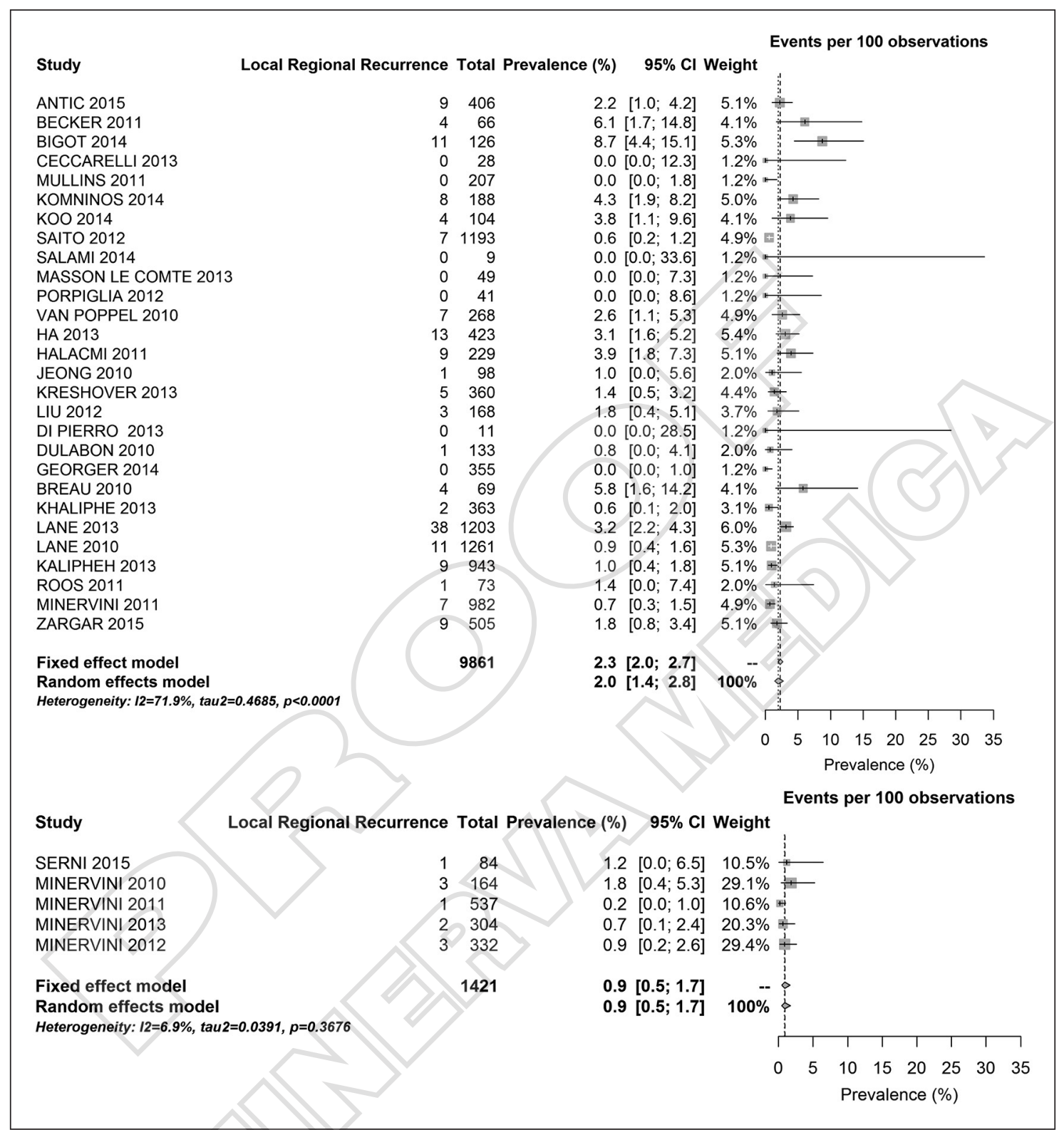

Figure 6.- Forest plot of the crude and pooled prevalences of loco-regional recurrence among the studies on standard partial nephrectomy and simple enucleation included in the review.

cluding that PN has no detrimental effect on CSS. 46

The prevalence of LRR in the SE group varied from $0 \%$ to $4 \%$. A recent prospective study on 304 patients evaluating the prognostic effect of capsule penetration on local recurrence after SE reported a crude LRR of nearly $1 \%$ at a median follow-up of 52 months. ${ }^{23}$ By conducting a random effect meta-analysis on the prevalence of LRR among the SPN and SE groups in studies with a minimum follow-up of 24 months, the pooled prevalence of $L R R$ was not significantly different between the two groups (Figure 6), ${ }^{14-64}$ as there was an evident overlap of the confidence interval in the pooled estimations between the two groups. In particular, the 


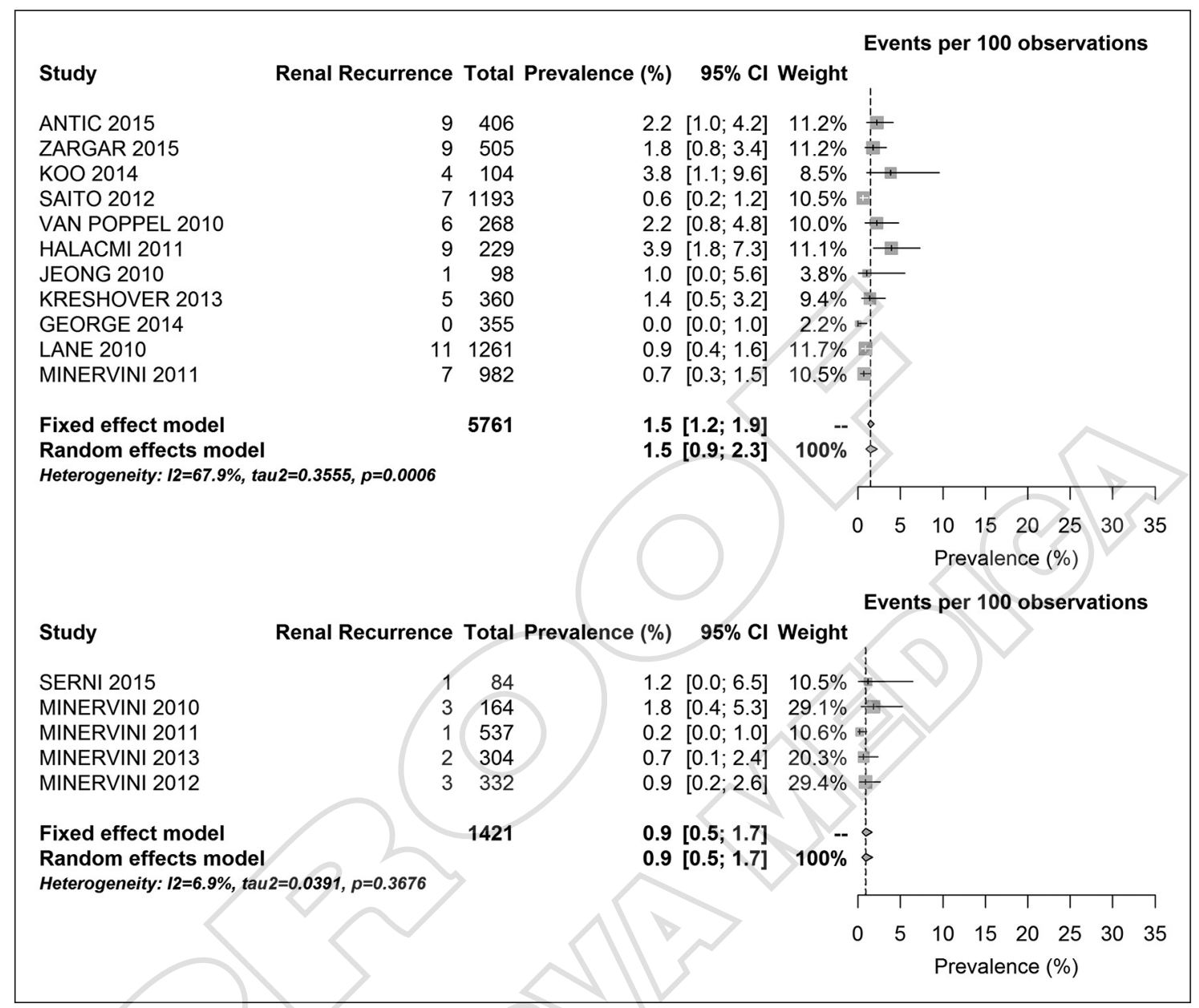

Figure 7.-Forest plot of the crude and pooled prevalences of renal recurrence among the studies on standard partial nephrectomy and simple enucleation included in the review.

pooled prevalence of LRR was $2.0 \%(95 \% \mathrm{CI}$ : $1.4-2.8 \%$, tau $\left.^{2}=0.48, \mathrm{I}^{2}=71.9 \%, \mathrm{P}<0.001\right)$ and $0.9 \%$ (95\% CI: $0.5-1,7 \%$, tau $^{2}=0-48, \mathrm{I}^{2}=6-9 \%$, $\mathrm{P}=0.04$ for the SPN and SE groups, respectively).

Finally, in the sensitivity analysis on renal recurrence, performed separately for those studies defining the exact anatomical location of recurrence, the prevalence of recurrence was $1.5 \%\left(95 \% \mathrm{CI}: 0.9-2.3 \%\right.$, tau $^{2}=0-04$ $\left.\mathrm{I}^{2}=67.9 \%, \mathrm{P}=0.001\right)$ and $0.9 \%(95 \% \mathrm{CI}: 0.5-$ $\left.1.7 \%, \operatorname{tau}^{2}=0.04 \mathrm{I} 2=6.9 \%, \mathrm{P}=0.40\right)$ for the $\mathrm{SPN}$ and SE groups, respectively (Figure 7). ${ }^{16-64}$

Overall, these findings offer the opportunity for further considerations. First, our results confirmed a low rate of both LRR and RER after PN that is comparable with that of recent reports on this topic. ${ }^{1,26}$ In this regard, it is important to highlight that the recurrence rate range after SPN was reduced when performing the analysis on RER instead of LRR ( $0-4 \%$ vs. $0-9 \%$ ), becoming comparable to that of SE ( $0-4 \%$, unvaried between the analyses on LRR and RER (Figures 6,7). This findings is confirmed by the reduction of the pooled prevalences of recurrence after SPN when considering the RER rate compared to those on LRR (pooled prevalences of $2.0 \%$ and $1.3 \%$, respectively, Figures 6, 7). Despite the limited number of studies included in our meta-analysis on RER, the reduced pooled prevalence of recurrence in the SPN group may be explained by a 
trend toward a homogenization of the patient population, mainly in terms of pT stage, across the studies reporting details on RER. At the same time, the pooled prevalences of recurrence after SE remained unchanged between the analyses on LRR and RER $(0.9 \%$ each, Figures 6,7$)$, confirming a more homogeneous patient population in this group.

In light of the previous results on the PSM rate, our meta-analysis confirms the non-inferiority of SE compared to SPN regarding the rate of both LRR and RER. This finding reflects the non-inferiority of SE compared to SPN with regard to PSM rate, reiterating the potential benefits of this technique ${ }^{8}$.

\section{Limitations and research needs of the study}

The studies included in this review have several limitations including inhomogeneity with regard to study design, quality of reporting and standardization of surgical approach. A relevant limitation of our study is that the quantitative analysis on the oncological outcomes after SE included series performed predominantly at a single Institution. 17, 22, 33, 49 This might theoretically raise concerns regarding the external validity and generalizability of the SE results in other patients cohorts. While our systematic review did identify other highquality, well-designed studies reporting oncological results of SE, they were excluded from the quantitative analysis due to the limited ( $<24$ months) length of follow-up. 34,35

Most studies included in our review are retrospective and did not define either standardized selection criteria for the choice of a specific RT nor the preoperative intent of the surgeon (resection strategy, RS). In this regard, the Surface-Intermediate-Base (SIB) Margin score has been proposed as a standardized reporting system of RTs during nephron-sparing surgery and was validated from a histopathological perspective showing that the visual definitions of RTs used to calculate the score are significantly associated with the thickness of healthy renal tissue beyond the peritumoral pseudocapsule at histopathological analysis. ${ }^{9}, 12$ Of note, an updated comprehensive reporting model stressed the importance of classifying even the preoperative intent of the surgeon into anatomic vs. nonanatomic RSs in addition to the SIB Margin score, as a key feature to characterize the intent of tumor excision during PN. ${ }^{8}$

Only one randomized trial was included in our final analysis. ${ }^{16}$ In this regard, although randomized controlled trials comparing SE and SPN may overcome the limitations of the current NSS literature, it is difficult to design such trials, as a standardized assessment of the RT can only be done a posteriori after surgery and not by randomization. 8,50

The definition of PSM is rarely reported within the published series. The lack of definition inherently hinders a meaningful comparison of different surgical series, as the possibility of false PSM (i.e. accidental violation of the tumor once it is removed from the surgical field or violation of the peritumoral pseudocapsule without leaving any malignant tissue in the resection bed) is almost never taken into consideration and therefore it might represent a biologically irrelevant bias when interpreting the study results. Moreover, there are no accepted definitions of local recurrence after PN in the current urologic literature. As such, the definition of LRR used for this review was based on the latest EAU Guidelines on RCC, but still it may not fully represent the spectrum of local recurrences after PN. Indeed, a hotly debated questions within the urological community is whether a specific RT is or is not associated with an increased risk of PSM and/or local recurrence. In order to answer this question, an objective and shared definition of the surgicalsite renal recurrence (SSR) is necessary. The lack of a shared definitions of LRR and RER within the PN literature limited the number of studies included in the quantitative analysis of recurrence rates and therefore the generalizability of the review results. Indeed, only 15 studies reported in details the exact anatomical site of local recurrence within the kidney and only two of these explicitly defined whether the renal recurrence occurred in the surgical resection bed (SSR) or elsewhere in the kidney (RER). ${ }^{17,} 48$ Of note, SSR and RER may theo- 
retically differ from a pathophysiological point of view, being a recurrence in the resection bed probably associated with the specific RT while RER with a specific tumor biology.

As such, this review could not perform a detailed quantitative analysis on the rate of SSR among the SE and SPN techniques. Moreover, even among the studies on SPN it was not possible to analyze the effect of a deeper healthy renal margin on the rate of SSR. Overall, the surgeon's preoperative intent (RS) might significantly determine the pattern of RTs performed at the time of PN and may affect each technique's results.

Overall, both the surgeon's preoperative intent (resection strategy, RS) and the final postoperative surgical result (RT), together with the specific site of local recurrence within the kidney should be accurately reported in future surgical series in order to establish the differential role of RT and other key surgical features on oncological outcomes after NSS8.

\section{Conclusions}

The goal of PN is complete excision of the tumor in an attempt to maximize the preservation of vascularized healthy renal parenchyma. However, no formal guidelines recommendations have been provided to date regarding the optimal RT to optimize cancer control and renal function preservation after PN.

Our systematic review and prevalance metaanalysis demonstrates that SE is at least noninferior to SPN for the treatment of malignant cT1-T2 renal tumors in regard to PSM, LRR and RER rates after a minumum follow-up of 24 months.

The current lack of uniform definitions of PSMs, tumor recurrence and resection techniques significantly undermine meaningful comparison of PN series and substantially limit the progress of urologic research in this field. As such, the use of standardized comprehensive models to report RS, RT and anatomical sites of local recurrence is imperative to the design future prospective trials evaluating the contribution of excision techniques such as SE or SPN in assessing oncologic outcomes following PN.

\section{References}

1. Ljungberg B, Bensalah AB, Canfield S, Giles RH, Kuczyk MA, Lam T, et al. EAU Guidelines on renal cell carcinoma 2016; 2016 [Internet]. Available from: http:// uroweb.org/guideline/renal-cell-carcinoma [cited 2017, Jun 6].

2. Motzer RJ, Jonasch E, Agarwal N, Beard C, Bhayani S, Bolger GB, et al. Kidney cancer, version 3.2015. J Natl Compr Canc Netw 2015;13:151-9.

3. Campbell SC, Gupta GN, Uzzo RG, Kutikov A. Re: Raj Satkunasivam, Sheaumei Tsai, Sumeet Syan, et al. Robotic Unclamped "Minimal-margin" Partial Nephrectomy: Ongoing Refinement of the Anatomic Zero-ischemia Concept. Eur Urol 2015;68:705-12.

4. Zhang Z, Zhao J, Dong W, Remer E, Li J, Demirjian S, et al. Acute Kidney Injury after Partial Nephrectomy: Role of Parenchymal Mass Reduction and Ischemia and Impact on Subsequent Functional Recovery. Eur Urol 2016;69:745-52.

5. Mir MC, Ercole C, Takagi T, Zhang Z, Velet L, Remer $\mathrm{EM}$, et al. Decline in renal function after partial nephrectomy: etiology and prevention. J Urol 2015;193:1889-98.

6. Volpe A, Blute ML, Ficarra V, Gill IS, Kutikov A, Porpiglia F, et al. Renal Ischemia and Function After Partial Nephrectomy: A Collaborative Review of the Literature. Eur Urol 2015;68:61-74.

7. Klatte T, Ficarra V, Gratzke C, Kaouk J, Kutikov A, Macchi V, et al. A Literature Review of Renal Surgical Anatomy and Surgical Strategies for Partial Nephrectomy. Eur Urol 2015;68:980-92.

8. Minervini A, Campi R, Serni S, Carini M. Re: Raj Satkunasivam, Sheaumei Tsai, Sumeet Syan, et al. Robotic Unclamped "Minimal-margin" Partial Nephrectomy: Ongoing Refinement of the Anatomic Zero-ischemia Concept. Eur Urol 2015;68:705-12.

9. Minervini A, Carini M, Uzzo RG, Campi R, Smaldone MC, Kutikov A. Standardized reporting of resection technique during nephron-sparing surgery: the surfaceintermediate-base margin score. Eur Urol 2014;66:803-5.

10. Gupta GN, Boris RS, Campbell SC, Zhang Z. Tumor Enucleation for Sporadic Localized Kidney Cancer: Pro and Con. J Urol 2015;194:623-5.

11. Moher D, Liberati A, Tetzlaff J, Altman DG, PRISMA Group. Preferred reporting items for systematic reviews and meta-analyses: the PRISMA statement. PLoS Med 2009;6:e1000097.

12. Minervini A, Campi R, Kutikov A, Montagnani I, Sessa F, Serni S, et al. Histopathological Validation of the Surface-Intermediate-Base Margin Score for Standardized Reporting of Resection Technique during Nephron Sparing Surgery. J Urol 2015;194:916-22.

13. Zhang MWB, Ho RCM, Cheung MWL, Fu E, Mak A. Prevalence of depressive symptoms in patients with chronic obstructive pulmonary disease: a systematic review, meta-analysis and meta-regression. Gen Hosp Psychiatry 2011;33:217-23.

14. Masson-Lecomte A, Yates DR, Bensalah K, Vaessen C, de la Taille A, Roumiguie M, et al. Robot-assisted laparoscopic nephron sparing surgery for tumors over $4 \mathrm{~cm}$ : operative results and preliminary oncologic outcomes from a multicentre French study. Eur J Surg Oncol 2013;39:799-803.

15. Porpiglia F, Fiori C, Bertolo R, Morra I, Russo R, Piccoli $\mathrm{G}$, et al. Long-term functional evaluation of the treated kidney in a prospective series of patients who underwent laparoscopic partial nephrectomy for small renal tumors. Eur Urol 2012;62:130-5.

16. Van Poppel H, Da Pozzo L, Albrecht W, Matveev V, Bono A, Borkowski A, et al. A prospective, randomised 
EORTC intergroup phase 3 study comparing the oncologic outcome of elective nephron-sparing surgery and radical nephrectomy for low-stage renal cell carcinoma. Eur Urol 2011;59:543-52.

17. Minervini A, Serni S, Tuccio A, Raspollini MR, Di Cristofano C, Siena G, et al. Local recurrence after tumor enucleation for renal cell carcinoma with no ablation of the tumor bed: results of a prospective single-centre study. BJU Int 2011;1071394-9.

18. Becker F, Roos FC, Janssen M, Brenner W, Hampel C, Siemer S, et al. Short-term functional and oncologic outcomes of nephron-sparing surgery for renal tumors $\geq 7$ cm. Eur Urol 2011;59:931-7.

19. Laryngakis NA, Van Arsdalen KN, Guzzo TJ, Malkowicz SB. Tumor enucleation: a safe treatment alternative for renal cell carcinoma. Expert Rev Anticancer Ther 2011;11:893-9.

20. Satkunasivam R, Tsai S, Syan S, Bernhard J-C, de Castro Abreu AL, Chopra S, et al. Robotic unclamped "minimalmargin" partial nephrectomy: ongoing refinement of the anatomic zero-ischemia concept. Eur Urol 2015;68:70512.

21. Simmons MN, Hillyer SP, Lee BH, Fergany AF, Kaouk J, Campbell SC. Functional recovery after partial nephrectomy: effects of volume loss and ischemic injury. J Urol 2012;187:1667-73.

22. Serni S, Vittori G, Frizzi J, Mari A, Siena G, Lapini A, et al. Simple enucleation for the treatment of highly complex renal tumors: Perioperative, functional and oncological results. Eur J Surg Oncol 2015;41:934-40.

23. Minervini A, di Cristofano C, Lapini A, Marchi M, Lanzi F, Giubilei G, et al. Histopathologic analysis of peritumoral pseudocapsule and surgical margin status after tumor enucleation for renal cell carcinoma. Eur Urol 2009;55:1410-8.

24. Azhar RA, de Castro Abreu AL, Broxham E, Sherrod A, Ma Y, Cai J, et al. Histological analysis of the kidney tumor-parenchyma interface. J Urol 2015;193:415-22.

25. Ficarra V, Galfano A, Cavalleri S. Is simple enucleation a minimal partial nephrectomy responding to the EAU guidelines' recommendations? Eur Urol 2009;55:1315-8.

26. Marszalek M, Carini M, Chlosta P, Jeschke K, Kirkali Z, Knuchel R, et al. Positive surgical margins after nephronsparing surgery. Eur Urol 2012;61:757-63.

27. Borghesi M, Brunocilla E, Schiavina R, Martorana G. Positive surgical margins after nephron-sparing surgery for renal cell carcinoma: incidence, clinical impact, and management. Clin Genitourin Cancer 2013;11:5-9.

28. Castilla EA, Liou LS, Abrahams NA, Fergany A, Rybicki LA, Myles J, et al. Prognostic importance of resection margin width after nephron-sparing surgery for renal cell carcinoma. Urology 2002;60:993-7.

29. Salami SS, George AK, Rais-Bahrami S, Okhunov Z, Waingankar N, Kavoussi LR. Off-clamp laparoscopic partial nephrectomy for hilar tumors: oncologic and renal functional outcomes. J Endourol 2014;28:191-5.

30. Antic T, Taxy JB. Partial nephrectomy for renal tumors: lack of correlation between margin status and local recurrence. Am J Clin Pathol 2015;143:645-51.

31. Saito H, Matsuda T, Tanabe K, Kawauchi A, Terachi T, Nakagawa K, et al. Surgical and oncologic outcomes of laparoscopic partial nephrectomy: a Japanese multi-institutional study of 1375 patients. J Endourol 2012;26:6529.

32. Kopp RP, Mehrazin R, Palazzi KL, Liss MA, Jabaji R, Mirheydar HS, et al. Survival outcomes after radical and partial nephrectomy for clinical T2 renal tumors categorised by R.E.N.A.L. nephrometry score. BJU Int 2014;114:708-18.

33. Minervini A, Ficarra V, Rocco F, Antonelli A, Bertini R, Carmignani G, et al. Simple enucleation is equivalent to traditional partial nephrectomy for renal cell carcinoma: results of a nonrandomized, retrospective, comparative study. J Urol 2011;185:1604-10.

34. Schiavina R, Serni S, Mari A, Antonelli A, Bertolo R, Bianchi $\mathrm{G}$, et al. A prospective, multicenter evaluation of predictive factors for positive surgical margins after nephron-sparing surgery for renal cell carcinoma: the RECORd1 Italian Project. Clin Genitourin Cancer 2015;13:165-70.

35. Longo N, Minervini A, Antonelli A, Bianchi G, Bocciardi AM, Cunico SC, et al. Simple enucleation versus standard partial nephrectomy for clinical T1 renal masses: perioperative outcomes based on a matched-pair comparison of 396 patients (RECORd project). Eur J Surg Oncol 2014;40:762-8.

36. Mukkamala A, Allam CL, Ellison JS, Hafez KS, Miller DC, Montgomery JS, et al. Tumor enucleation vs. sharp excision in minimally invasive partial nephrectomy: technical benefit without impact on functional or oncologic outcomes. Urology 2014;83:1294-9.

37. Minervini A, Serni S, Di Cristofano C, Carini M. Rebuttal from authors re: Vincenzo Ficarra, Antonio Galfano and Stefano Cavalleri. Is simple enucleation a minimal partial nephrectomy responding to the EAU guidelines' recommendations? Eur Urol 2009;55:1315-8.

38. Fergany AF, Hafez KS, Novick AC. Long-term results of nephron sparing surgery for localized renal cell carcinoma: 10-year followup. J Urol 2000;163:442-5.

39. Khalifeh A, Autorino R, Hillyer SP, Laydner H, Eyraud $\mathrm{R}$, Panumatrassamee $\mathrm{K}$, et al. Comparative outcomes and assessment of trifecta in 500 robotic and laparoscopic partial nephrectomy cases: a single surgeon experience. J Urol 2013;189:1236-42.

40. Khalifeh A, Kaouk JH, Bhayani S, Rogers C, Stifelman M, Tanagho YS, et al. Positive surgical margins in robot-assisted partial nephrectomy: a multi-institutional analysis of oncologic outcomes (leave no tumor behind). J Urol 2013;190:1674-9.

41. Bensalah K, Pantuck AJ, Rioux-Leclercq N, Thuret R, Montorsi F, Karakiewicz PI, et al. Positive surgical margin appears to have negligible impact on survival of renal cell carcinomas treated by nephron-sparing surgery. Eur Urol 2010;57:466-71.

42. Pertia A, Managadze L. Long-term results of simple enucleation for the treatment of small renal cell carcinoma. Int Braz J Urol 2006;32:640-7.

43. Minervini A, Raspollini MR, Tuccio A, Di Cristofano C, Siena G, Salvi M, et al. Pathological characteristics and prognostic effect of peritumoral capsule penetration in renal cell carcinoma after tumor enucleation. Urol Oncol 2014;32:50.e15-22.

44. Jeong SJ, Kim KT, Chung MS, Hong SK, Byun S-S, Lee SE. The prognostic value of the width of the surgical margin in the enucleoresection of small renal cell carcinoma: an intermediate-term follow-up. Urology 2010;76:58792.

45. Bigot P, Hetet J-F, Bernhard J-C, Fardoun T, Audenet F, Xylinas E, et al. Nephron-sparing surgery for renal tumors measuring more than $7 \mathrm{~cm}$ : morbidity, and functional and oncological outcomes. Clin Genitourin Cancer 2014;12:e19-27.

46. Alanee S, Nutt M, Moore A, Holland B, Dynda D, Wilber A, et al. Partial nephrectomy for T2 renal masses: contemporary trends and oncologic efficacy. Int Urol Nephrol. 2015;47:945-50.

47. Mullins JK, Feng T, Pierorazio PM, Patel HD, Hyams ES, Allaf ME. Comparative analysis of minimally invasive partial nephrectomy techniques in the treatment of localized renal tumors. Urology 2012;80:316-21.

48. Zargar-Shoshtari K, Kim T, Simon R, Lin H-Y, Yue B, Sharma P, et al. Surveillance Following Nephron-Sparing 
Surgery: An Assessment of Recurrence Patterns and Surveillance Costs. Urology 2015;86:321-6.

49. Minervini A, Serni S, Tuccio A, Siena G, Vittori G, Masieri L, et al. Simple enucleation versus radical nephrectomy in the treatment of pT1a and pT1b renal cell carcinoma. Ann Surg Oncol 2012;19:694-700.

50. Briganti A, Giannarini G, Karnes RJ, Gandaglia G, Ficarra V, Montorsi F. What evidence do we need to support the use of extended pelvic lymph node dissection in prostate cancer? Eur Urol 2015;67:597-8.

51. Ceccarelli G, Codacci-Pisanelli M, Patriti A, Ceribelli C, Biancafarina A, Casciola L. Robotic-assisted transperitoneal nephron-sparing surgery for small renal masses with associated surgical procedures: surgical technique and preliminary experience. Updates Surg. 2013;65:183-90.

52. Komninos C, Shin TY, Tuliao P, Kim DK, Han WK, Chung BH, et al. Robotic partial nephrectomy for completely endophytic renal tumors: complications and functional and oncologic outcomes during a 4-year median period of follow-up. Urology 2014;84:1367-73.

53. Koo KC, Kim JC, Cho KS, Choi YD, Hong SJ, Yang SC, et al. Oncological outcomes after partial vs. radical nephrectomy in renal cell carcinomas of $\leq 7 \mathrm{~cm}$ with presumed renal sinus fat invasion on preoperative imaging. BJU Int 2016;117:87-93.

54. Ha Y-S, Park YH, Kang SH, Hong S-H, Hwang T-K, Byun $\mathrm{S}-\mathrm{S}$, et al. Predictive factors for late recurrence in patients with stage T1 clear cell renal cell carcinoma: a multiinstitutional study. Clin Genitourin Cancer 2013;11:51-5.

55. Halachmi S, Moskovitz B, Farfara R, Nativ O. Predictors and mechanisms of oncological failure following nephron-sparing surgery for renal cancer. Isr Med Assoc J 2011;13:166-71.

56. Kreshover JE, Richstone L, Kavoussi LR. Renal cell recurrence for $\mathrm{T} 1$ tumors after laparoscopic partial nephrectomy. J Endourol 2013;27:1468-70.

57. Liu Z, Wang P, Xia D, Lou Y-F, Pan H-F, Wang S. Comparison between laparoscopic and open partial nephrectomy: surgical, oncologic, and functional outcomes. Kaohsiung J Med Sci 2013;29:624-8.

58. Di Pierro GB, Tartaglia N, Aresu L, Polara A, Cielo A, Cristini $\mathrm{C}$, et al. Laparoscopic partial nephrectomy for endophytic hilar tumors: feasibility and outcomes. Eur J Surg Oncol 2014;40:769-74.

59. Dulabon LM, Kaouk JH, Haber G-P, Berkman DS, Rogers CG, Petros F, et al. Multi-institutional analysis of robotic partial nephrectomy for hilar versus nonhilar lesions in 446 consecutive cases. Eur Urol 2011;59:32530 .

60. George AK, Herati AS, Rais-Bahrami S, Waingankar N, Kavoussi LR. Laparoscopic partial nephrectomy for hilar tumors: oncologic and renal functional outcomes. Urology 2014;83:111-5.

61. Breau RH, Crispen PL, Jimenez RE, Lohse CM, Blute ML, Leibovich BC. Outcome of stage T2 or greater renal cell cancer treated with partial nephrectomy. J Urol 2010;183:903-8.

62. Lane BR, Campbell SC, Gill IS. 10-year oncologic outcomes after laparoscopic and open partial nephrectomy. J Urol 2013;190:44-9.

63. Lane BR, Gill IS. 7-year oncological outcomes after laparoscopic and open partial nephrectomy. J Urol 2010;183:473-9.

64. Roos FC, Brenner W, Muller M, Schubert C, Jager WJ, Thuroff JW, et al. Oncologic long-term outcome of elective nephron-sparing surgery versus radical nephrectomy in patients with renal cell carcinoma stage $\mathrm{pT} 1 \mathrm{~b}$ or greater in a matched-pair cohort. Urology 2011;77:803-8.

Conflicts of interest.-The authors certify that there is no conflict of interest with any financial organization regarding the material discussed in the manuscript.

Article first published online: January 26, 2017.

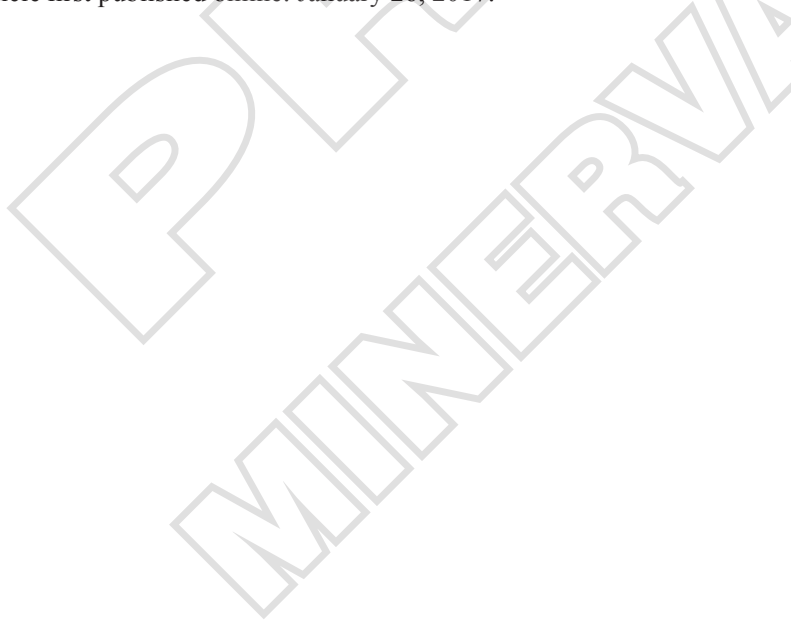

